\title{
Research of Potential Distribution Defect about 220kV Porcelain-clad Arrester for Heavy Contamination Areas
}

\author{
Lina Geng ${ }^{1}$, Yafeng Zhong ${ }^{1}$ and Hui Geng ${ }^{2}$ \\ ${ }^{1}$ Electric Power Research Institute of State Grid Liaoning Electric Power Co.,Ltd., Shenyang, Liaoning 110006, China \\ ${ }^{2}$ Maintenance Company of State Grid Liaoning Electric Power Co.,Ltd., Shenyang, Liaoning 110006, China
}

\begin{abstract}
This paper used $220 \mathrm{kV}$ porcelain-clad arrester defect at heavy contamination areas as a case, to research potential distribution by the means of high-pressure test and simulation. It has comprehensive analyzed the reasons that the defect of the arrester design is unreasonable. The paper reseached potential distribution of the new design arrester for heavy contamination areas. At last, the paper gives reasonable structure of $220 \mathrm{kV}$ Porcelain-clad Arrester for heavy contamination areas to ensure the system safe and stable operation.
\end{abstract}

Keywords-arrester; heavy contamination areas; potential distribution; uniformity coefficient calculation

\section{INTRODUCTION}

Gapless metal oxide surge arresters (MOA) with its exceptionally well nonlinearities gained wide application in electric power system ${ }^{[1]}$. For gapless MOA, in the operation the assume continuous operating voltage of resistor near the high voltage side of the arrester units is higher than the other side ${ }^{[2]}$, because of the presence of stray capacitance without effective measures. The condition led to the aging rate of varistor accelerated of this part ${ }^{[3]}$, severe enough to cause thermal runaway. Therefore, it must take reasonable measures to improve its voltage distribution. It has its significance to ensure MOA safe and stable operation.

\section{THE CASE OVERVIEW}

February 2013, 220kV porcelain MOA for heavy dirty areas failure events occurred in the system. The event arrester was E-class filthy level, creepage distance $7812 \mathrm{~mm}$, each section MOA height was $1.65 \mathrm{~m}, 0.35 \mathrm{~m}$ higher than normal section of $1.3 \mathrm{~m}$, the whole MOA total 0.7 meters higher than normal one. We analyzed the fault after tests and disintegration. The fault was due to the irrational internal structure, resulting that the resistor column potential distribution uneven caused MOA fault. We improved arrester fault structure in order to uniform MOA potential distribution to meet the need for field operation.

Arrester model is Y10W1-204/532GW, divided into upper and lower sections, the structure and dimensions shown in Figure 1. This paper will do comparison studies of the original fault structure (structure 1) and the new improved structure (structure 2).
Structure 1: MOA each section containing 29 resistors, resistor diameter $\Phi 51$; average thickness is $25.09 \mathrm{~mm}$; the top of the MOA has a diameter of $1.2 \mathrm{~m}, 0.5 \mathrm{~m}$ of depth grading ring; height of $1.65 \mathrm{~m}$, two sections totaling $3.3 \mathrm{~m}$; the support catheter at the lower part of each section resistor column is $410 \mathrm{~mm}$ high; the bottom of the frame height of $1.8 \mathrm{~m}$.

Structure 2: model, size and appearance are same with structure 1 , but in the internal structure the support catheter at the lower part of each section resistor column is $210 \mathrm{~mm}$ high.

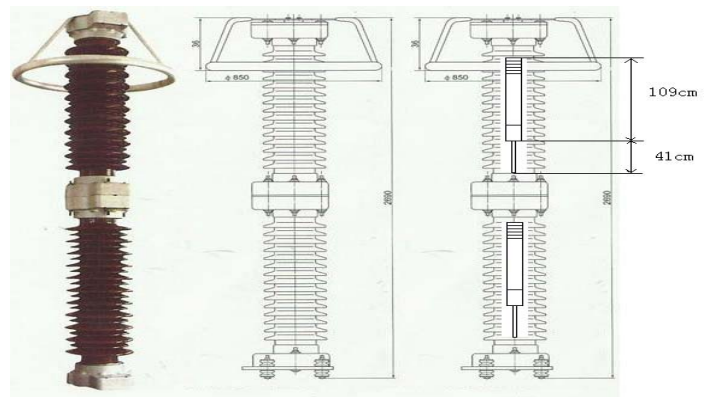

FIGURE I. STRUCTURE 1 ARRESTER

\section{CALCUlation}

Using the finite element method $^{[4-7]}$ of the three-dimensional electrostatic field solved principle to calculate MOA three-dimensional electric field distribution. Each section of MOA select seven points: from the beginning of the lower flange of each section $0,1,2, \ldots, 6$. Point " 0 " is under the first resistor from the lower flange. Point " 1 " is between the resistor 5 and 6 , and so on. Point "6" is at the upper side of the resistor 29 , contact with the metal pad of the flange. Table I and Table II given every point of leakage current calculated value, Figures 2-5 displayed the MOA potential and the electric field distribution under the two structures.

TABLE I. STRUCTURE 1 RESULTS

\begin{tabular}{|c|c|c|c|}
\hline $\begin{array}{c}\text { Resistor } \\
\text { number }\end{array}$ & Point & $\begin{array}{c}\text { Current } \\
\text { calculated } \\
\text { value of upper } \\
\text { section }\end{array}$ & $\begin{array}{c}\text { Current } \\
\text { calculated } \\
\text { value of lower } \\
\text { section }\end{array}$ \\
\hline $0-1$ & 0 & 0.51 & 0.48 \\
\hline $5-6$ & 1 & 0.5 & 0.46 \\
\hline $10-11$ & 2 & 0.49 & 0.43 \\
\hline
\end{tabular}




\begin{tabular}{|c|c|c|c|}
\hline $15-16$ & 3 & 0.45 & 0.4 \\
\hline $20-21$ & 4 & 0.45 & 0.4 \\
\hline $25-26$ & 5 & 0.45 & 0.44 \\
\hline 29 & 6 & 0.446 & 0.46 \\
\hline
\end{tabular}

TABLE II. STRUCTURE 2 RESULTS

\begin{tabular}{|c|c|c|c|}
\hline $\begin{array}{c}\text { Resistor } \\
\text { number }\end{array}$ & Point & $\begin{array}{c}\text { Current } \\
\text { calculated } \\
\text { value of upper } \\
\text { section }\end{array}$ & $\begin{array}{c}\text { Current } \\
\text { calculated } \\
\text { value of lower } \\
\text { section }\end{array}$ \\
\hline $0-1$ & 0 & 0.47 & 0.42 \\
\hline $5-6$ & 1 & 0.45 & 0.39 \\
\hline $10-11$ & 2 & 0.45 & 0.37 \\
\hline $15-16$ & 3 & 0.46 & 0.37 \\
\hline $20-21$ & 4 & 0.46 & 0.37 \\
\hline $25-26$ & 5 & 0.46 & 0.37 \\
\hline 29 & 6 & 0.47 & 0.4 \\
\hline
\end{tabular}

Unit: $\mathrm{mA}$ (rms)

Calculations show that the leakage current of structure 2 is more uniformity than structure 1. From the figure of voltage distribution we can see that potential distribution of structure 2 is more uniformity than structure 1. Figure of electric field distribution shows that the electric field between the MOA resistor, aluminum pads and metal tube of structure 1 upper section is relative concentration more than structure 2, especially at the junction of the first resistor with a metal pipe, the electric field has relatively high field strength and exhibits unevenness.

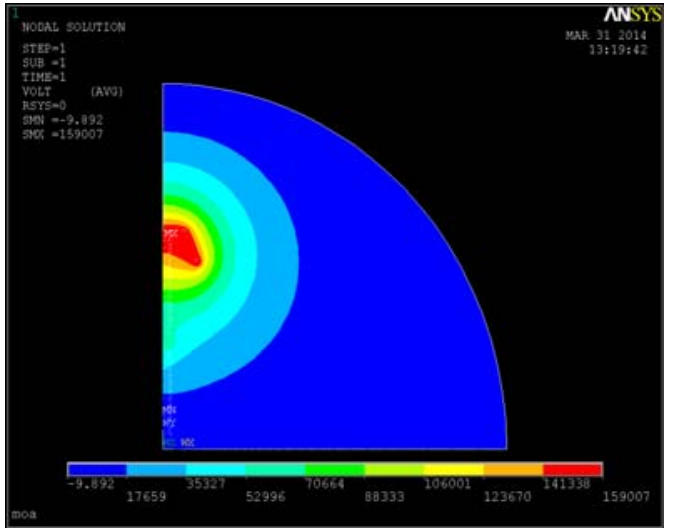

FIGURE II. POTENTIAL DISTRIBUTION OF STRUCTURE 1

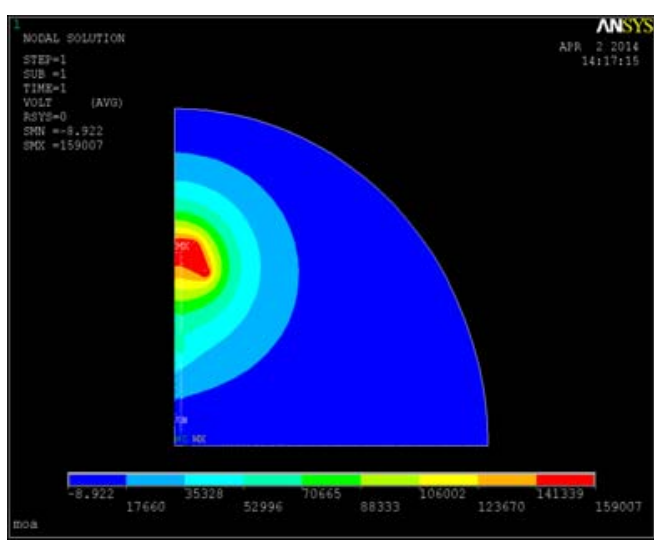

FIGURE III. POTENTIAL DISTRIBUTION OF STRUCTURE 2

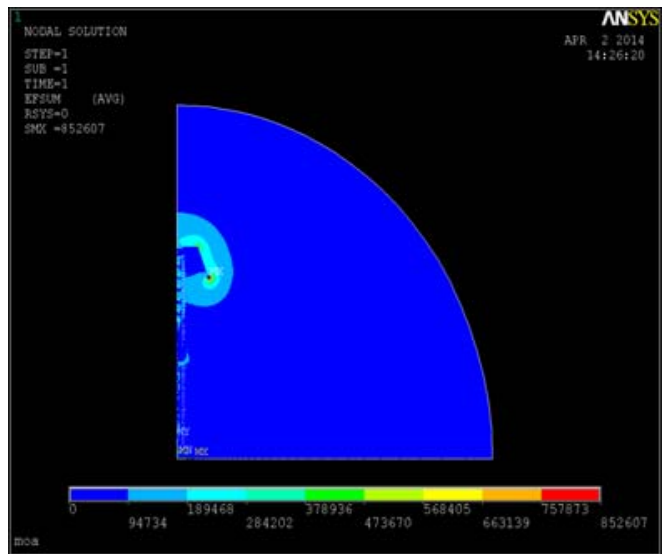

FIGURE IV. ELECTRIC FIELD DISTRIBUTION OF STRUCTURE 1

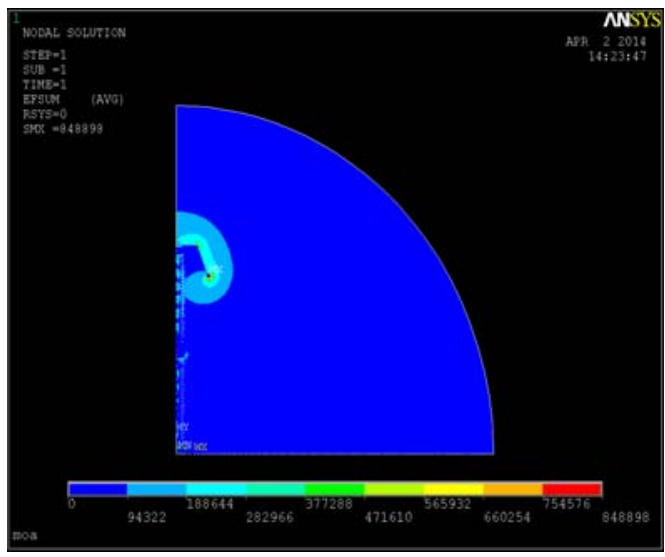

FIGURE V. ELECTRIC FIELD DISTRIBUTION OF STRUCTURE 2

\section{EXPERIMENTAL RESEARCH}

Using fiber-current method to test leakage current, the test voltage: $50 \mathrm{~Hz}, 159 \mathrm{kV}(\mathrm{rms})$.

In order to facilitate comparative analysis, measuring points selected the same points[8-10] with the calculation points. Each section choose seven measurement points respectively in the structure 1 and the structure $2 \mathrm{MOA}$.

Tables III and IV showed comparison of measured and calculated values about two structures. As it can be seen from the data in the table, calculated and measured values coincide.

TABLE III. COMPARISON OF MEASURED AND CALCULATED VALUES OF STRUCTURE 1

\begin{tabular}{|c|c|c|c|c|c|}
\hline \multirow{2}{*}{$\begin{array}{c}\text { Resisto } \\
\text { r } \\
\text { numbe } \\
\text { r }\end{array}$} & Poin & \multicolumn{2}{|c|}{$\begin{array}{c}\text { Current calculated } \\
\text { value of upper section }\end{array}$} & \multicolumn{2}{c|}{$\begin{array}{r}\text { Current calculated } \\
\text { value of } \\
\text { lower } \\
\text { section }\end{array}$} \\
\cline { 3 - 6 } & & $\begin{array}{c}\text { Measure } \\
\text { d values }\end{array}$ & $\begin{array}{c}\text { Calculate } \\
\text { d values }\end{array}$ & $\begin{array}{c}\text { Measure } \\
\text { d values }\end{array}$ & $\begin{array}{c}\text { Calculate } \\
\text { d values }\end{array}$ \\
\hline $0-1$ & 0 & 0.495 & 0.51 & 0.437 & 0.48 \\
\hline $5-6$ & 1 & 0.462 & 0.5 & 0.407 & 0.46 \\
\hline $10-11$ & 2 & 0.450 & 0.49 & 0.383 & 0.43 \\
\hline
\end{tabular}




\begin{tabular}{|c|c|c|c|c|c|}
\hline $15-16$ & 3 & 0.443 & 0.45 & 0.380 & 0.4 \\
\hline $20-21$ & 4 & 0.447 & 0.45 & 0.380 & 0.4 \\
\hline $25-26$ & 5 & 0.445 & 0.45 & 0.394 & 0.44 \\
\hline 29 & 6 & 0.455 & 0.446 & 0.409 & 0.46 \\
\hline
\end{tabular}

Unit: $\mathrm{mA}$ (rms)

TABLE IV. COMPARISON OF MEASURED AND CALCULATED VALUES OF STRUCTURE 2

\begin{tabular}{|c|c|c|c|c|c|}
\hline \multirow{2}{*}{$\begin{array}{c}\text { Resistor } \\
\text { number }\end{array}$} & \multirow{2}{*}{$\begin{array}{c}\text { Poi } \\
\text { nt }\end{array}$} & \multicolumn{2}{|c|}{$\begin{array}{c}\text { Current calculated } \\
\text { value of upper section }\end{array}$} & \multicolumn{2}{c|}{$\begin{array}{c}\text { Current calculated } \\
\text { value of }\end{array}$} \\
\cline { 3 - 6 } & & $\begin{array}{c}\text { Measured } \\
\text { values }\end{array}$ & $\begin{array}{c}\text { Calculate } \\
\text { d values }\end{array}$ & $\begin{array}{c}\text { Measured } \\
\text { values }\end{array}$ & $\begin{array}{c}\text { Calculate } \\
\text { d values }\end{array}$ \\
\hline $0-1$ & 0 & 0.460 & 0.47 & 0.404 & 0.42 \\
\hline $5-6$ & 1 & 0.445 & 0.45 & 0.382 & 0.39 \\
\hline $10-11$ & 2 & 0.453 & 0.45 & 0.366 & 0.37 \\
\hline $15-16$ & 3 & 0.462 & 0.46 & 0.361 & 0.37 \\
\hline $20-21$ & 4 & 0.463 & 0.46 & 0.366 & 0.37 \\
\hline $25-26$ & 5 & 0.465 & 0.46 & 0.375 & 0.37 \\
\hline 29 & 6 & 0.474 & 0.47 & 0.392 & 0.4 \\
\hline
\end{tabular}

Unit: $\mathrm{mA}$ (rms)

\section{Potential Uniformity CoefFicient Calculation}

MOA potential uniformity coefficient is calculated according to the following method:

$$
K=(1+K v)(1+3 K c)-1
$$

In the formula, $\mathrm{Kv}$ is the voltage distribution uniformity coefficient caused by stray capacitance, the formula is

$$
K_{\mathrm{y}}=\left(\frac{U_{i} \times C_{i}}{\bar{C}}-\mathrm{U}_{\mathrm{c}} / \mathrm{n}\right) /\left(\mathrm{U}_{\mathrm{c}} / \mathrm{n}\right)
$$

In the formula, $i=1,2,3, \ldots, n$. Takes the maximum value of Kv.

$K \mathrm{c}$ is the voltage distribution uniformity coefficient caused by resistor capacitance dispersion, the formula is

$$
\pi_{c}=\sqrt{(1 / \mathrm{n}-1) \sum_{\mathrm{i}=1}^{\mathrm{n}}\left(\mathrm{C}_{1}-C\right)^{2}} / C=\sigma / C
$$

$\mathrm{U}_{\mathrm{i}}$-The voltage across the $\mathrm{i}$ resistor (in terms of average thickness)

$\mathrm{C}_{\mathrm{i}}$-The capacitance value of the $\mathrm{i}$ resistor (in terms of average thickness)

$\bar{C}$-The average capacitance value of all resistors (in terms of average thickness)

$\mathrm{U}_{\mathrm{c}}$-The continuous operating voltage of MOAn -The quantity of resistors in MOA

$\sigma-$ The capacitance mean variance of resistors

$$
\text { Because of } I_{i}=U_{i} \times C_{i} \times 2 \pi f
$$

Equation formula (4) into the formula (2) to be

$$
K_{\mathrm{v}}=\left(\frac{I_{i}}{2 \pi f \bar{C}}-\frac{U c}{n}\right) /\left(\frac{U c}{n}\right)=\frac{I_{i} \times n}{2 \pi f \bar{C} U c}-1
$$

After capacitance tested and Calculated, we got

$$
\begin{aligned}
& \bar{C}=522.11 \mathrm{pf}, \quad \mathrm{U}_{\mathrm{c}}=159 \mathrm{kV}, \quad \mathrm{f}=50 \mathrm{~Hz}, \quad \mathrm{n}=58 . \\
& \mathrm{I}_{\text {ideal }}=0.449 \mathrm{~mA} .
\end{aligned}
$$

Substituting parameters into the formulas above, the calculated results are $\mathrm{K} 1=0.12$ (voltage uneven distribution coefficients of structure 1); K2=0.075 ( voltage uneven distribution coefficients of structure 2).

Figure VI and VII are potential distribution curves of structure 1 and structure 2 MOA.

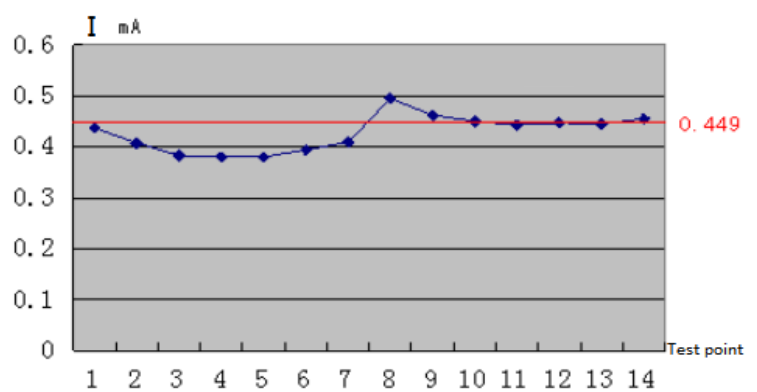

FIGURE VI. POTENTIAL DISTRIBUTION CURVES OF STRUCTURE 1

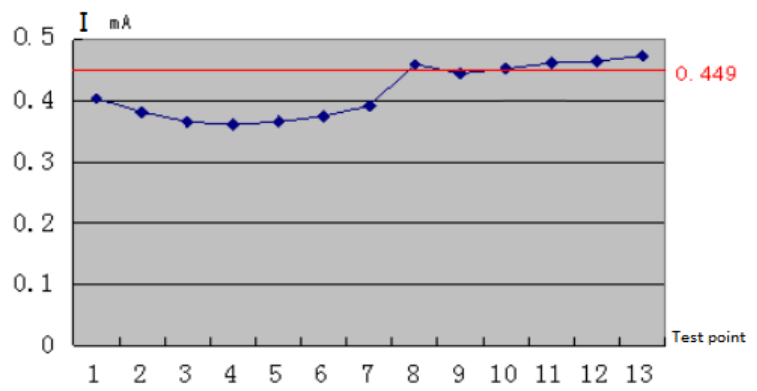

FIGURE VII. POTENTIAL DISTRIBUTION CURVES OF STRUCTURE 2

\section{CONCLUSION}

Tables I and III showed that the tested and calculated maximum current of structure 1 appear in point " 0 " position, which between the last piece resistor and the metal support item, at the bottom of the upper section. Withstanding voltage of this point comes from three aspect. First, it comes from continuous operating voltage of each piece resistor; Second, it comes from the potential difference between the longer $(410 \mathrm{~mm})$ metal support and the same position on porcelain coat of MOA; Third, it comes from stray capacitance with resistor to ground, which subjects to continuous operating voltage change. Therefore, potential distribution uniformity coefficient of structure 1 exceeds MOA normally required standard value 0.10 . 
Tables II and IV showed that the tested and calculated maximum current of structure 2 appear in point "29" position, which between the first piece resistor and the metal support item, at the top of the upper section. After equalizing measures taken by the general MOA, MOA voltage distribution is still in condition owed compensation, the top of the upper section assumed voltage relatively higher than the bottom of upper section, and the lower section assumed voltage lower than the upper section.

In summary, potential distribution uniformity coefficient of structure 2 MOA is 0.075 . According to calculations and experimental results, $220 \mathrm{kV}$ porcelain coat MOA for heavy contamination areas use structure 2 , to ensure the system safe and stable operation.

\section{REFERENCES}

[1] ANSYS Inc. CFX User Defined Function Manual. 2003

[2] He Jinliang, Zeng Rong, Chen Shuiming, et al. Potential distribution analysis of suspended-type metal-oxide surge arresters. IEEE Transactions on Power Delivery . 2003

[3] Liu Xuezhong, Liu Fuyi.The influence of varistor disk capaci-tance of MOA arrester onit $s$ voltage distribution. Proceed of the6thInternationnal Conference on Properties and Applica-tions of Dielectric Materials . 2000

[4] Kumar U, Mogaveera V. Voltage distribution studies on $\mathrm{ZnO}$ arresters. IEE Proceedings C Generation Transmission and Distribution . 2002

[5] Koji ma S, Oymam M. Potential distribution of mental oxide surge arresters under carious environmental conditions. IEEE Transactions on Power Delivery . 1988

[6] Han S J, Zou J, Gu S Q, et al. Calculation of the potential distribution of high voltage metal oxide arrester by using an $\mathrm{i}$ m-proved semi-analytic finite element method. IEEE Transactions on Magnetics . 2005

[7] Vitor Mal Machado. Axisymmetric eddy current problems u-sing a special hybrid FE/BE method. IEEE Trans on Mag-netics . 2003

[8] Yue Yali, Jiangshao Cheng, Zhang Yuan Bin. MOA Distribution Numerical analysis and measurement potential of $800 \mathrm{kV}[\mathrm{J}]$. High Voltage Electric. 2009 (04)

[9] Wang Qiong, An Chuichui, Ma Wenling, Dou Xiaojing, Liu Hang, Zhang Yuan Bin study [J]. Potentials of $1000 \mathrm{kV}$ porcelain coat MOA resistors and high-voltage electrical porcelain. 2008 (06)

[10] Guo Jie, HE Jimou, Li Xiaofeng. $750 \mathrm{kV}$ MOA potential distribution study [J]. Chinese power. $2006(01)$ 